DOI: $10.12731 / 2070-7568-2020-4-85-102$ УДК 351

\title{
ИСПОЛЬЗОВАНИЕ «СКВОЗНЫХ» ЦИФРОВЫХ ТЕХНОЛОГИЙ В СФЕРЕ ГОСУДАРСТВЕННОГО УПРАВЛЕНИЯ
}

Катрашова Ю.В., Митяшин Г.Ю.

В данной статье рассмотрены «сквозные» иифровые технологии в аспекте их применения в системе государственного управления. Определены наиболее перспективные направления реализации программ ичифрового развития. Упомянутье авторами «сквозные» ичировые технологии, по их мнению, являются ключевыми для обеспечения технологической независимости государства будущего. В работе представлено описание каждой отдельной технологии и обоснованы преимущества ее интегращии в систему органов власти.

Цель статьи: выявление сфер применения сквозных ичифровых технологий в государственном управлении.

Методология проведения работы: в статье использовался общенаучный метод анализа и синтеза, а также метод установления причинно-следственных связей.

Результаты: обоснована эффективность применения «сквозныху ичифровых технологий в государственном управлении и выявлены преимущества и риски.

Область применения результатов: полученные результаты работы ияелесообразно применять в государственных органах для повышения эффективности принятия управленческих решений.

Ключевые слова: изифровая трансформация; государственное управление; информационные технологии; блокчейн; искусственный интеллект; большие данные.

\section{THE USE OF "PASS-THROUGH" OF DIGITAL TECHNOLOGY IN THE FIELD OF PUBLIC ADMINISTRATION}

Katrashova Yu.V., Mityashin G. Yu.

This article discusses "end-to-end" digital technologies in the aspect of their application in the public administration system. The most Promising 
areas of implementation of digital development programs are identified. The" end-to-end " digital technologies mentioned by the authors, in their opinion, are key to ensuring the technological independence of the state of the future. The paper presents a description of each individual technology and justifies the advantages of its integration into the government system.

Purpose: identification of areas of application of end-to-end digital technologies in public administration.

Methodology: in this article General scientific method of analysis and synthesis and method of establishing cause-and-effect relationships were used.

Results: the effectiveness of using "end-to-end" digital technologies in public administration is proved, and the advantages and risks are identified.

Practical implications: the results obtained should be applied in government agencies to improve the efficiency of managerial decision-making.

Keywords: digital transformation; public administration; information technology; blockchain' artificial intelligence; Big Data.

\section{Введение}

Появление цифровых технологий существенным образом поменяло парадигму технологического уклада и внесло свои коррективы в различные сферы жизни человека $[21,26]$. Государство как институт политической власти, регулирующий социальные отношения, также претерпевает цифровую трансформацию, вызванную Четвертой промышленной революцией [29]. Для того, чтобы осуществлять эффективное управление обществом в целом и отдельными социальными группами, государству необходимо адаптироваться к изменениям и исполнять свои функции, ориентируясь на новые модели поведения. В рамках Индустрии 4.0 интеграция цифровых решений в управленческие, социальные и бизнес-процессы (G2B, $\mathrm{G} 2 \mathrm{C}, \mathrm{G} 2 \mathrm{G}$, ) является основой для реализации федеральных и региональных программ по социально-экономическому развитию страны.

Цифровая трансформация, ведущая к реорганизации работы органов власти с использованием цифровых технологий и алгорит- 
мов, определяет принципы «гибкого управления», суть которых заключается в поддерживании механизма работы бесперебойной обратной связи в течение всего срока осуществления планов государственных программ [6].

Тенденция перехода к цифровому государству подразумевает собой формирование организационной структуры административных органов на базе единой платформы, обеспечивающей удобное взаимодействие между субъектами и объектами управления [3, 16, 23]. Такой подход представляет собой создание комплексной целостной системы, основанной на информационных данных и ориентированной на граждан $[8,14]$. Вследствие этого возникает необходимость в компетентных кадровых ресурсах, составлении нормативной базы, модернизации органов власти, направленной на реализацию сервисной модели деятельности. Таким образом, государство становится поставщиком услуг для физических и юридических лиц, что повышает уровень благосостояния населения за счет удобства, возникающего как результат более прозрачных, открытых решений подотчетного управления [13].

Активное внедрение цифровых технологий в систему государственного управления преследует цель оптимизации производственных процессов, эффективной обработки информационных данных, повышения эффективности предоставления государственных услуг в режиме реального времени, расширения возможностей защиты прав, повышения культуры граждан в контексте осведомленности о нормативно-правовых актах [28].

Среди многообразия цифровых технологий выделяют «сквозные» цифровые технологии. Это наиболее перспективные технологии, которые способны радикально изменить уклад жизни общества, главным образом включая политическую и экономическую подсистемы. Для развития сквозных технологий был сформирован проект «Цифровые технологии», нацеленный на создание системы поддержки поисковых, прикладных исследований в области цифровой экономики, обеспечивающей технологическую независимость по направлениям сквозных цифровых технологий, конкурентоспособных на глобальном уровне, и национальную безопасность $[18,19]$. 
Ключевыми «сквозными» технологиями применительно к системе государственного управления являются следующие: большие данные (Big Data), искусственный интеллект (нейросети), блокчейн (системы распределенного реестра) и квантовые сети.

С учетом важности сквозных цифровых технологий для повышения эффективности государственного управления необходимо понимать потенциал и ограничения этих технологий. В данной статье мы рассмотрим каждую технологию и возможности ее использования более подробно.

\section{Искусственный интеллект и большие данные}

Наиболее перспективными направлениями с точки зрения интеграции ИИ являются следующие предметные области: безопасность, сервисные функции государства, контроль и надзор, предиктивная аналитика, стратегическое целеполагание и законотворчество, функционирование инфраструктур [10]. К примеру, в сфере безопасности на основе ИИ будет возможно при помощи машинного обучения распознавать лица преступников и идентифицировать их личности, упростив задачу поиска полицейским работникам. Данное решение уже имело применение в рамках Чемпионата мира по футболу 2018 года, когда полиции удалось задержать порядка 180 подозреваемых при помощи технологии FindFace российской компании NtechLab, которая считается одной из лучших в мире [15]. В аспекте повышения качества предоставляемых услуг населению на основе применения ИИ предоставление госуслуг станет проактивным - обработка обращений граждан будет производиться значительно быстрее и качественнее [16]. Разработав определенную модель данных и «научив» ее давать оценку параметров экспертных решений, станет реально осуществлять целеполагание с учетом комплексного анализа всех факторов и определять основные задачи стратегического планирования [9]. Осуществление задач инфраструктуры с использованием роботизированных систем приведет к автоматизации производственных процессов промышленной отрасли, 
а также к развитию автономного транспорта (например, беспилотное грузовое сообщение). Применение искусственного интеллекта в осуществлении управленческой деятельности ставит под вопрос реформирование кадрового резерва должностей госструктур. Высока вероятность исключения многих чиновников, ведь с их задачами намного быстрее и качественнее будет справляться искусственный интеллект.

Искусственный интеллект (ИИ) способен давать высокоэффективные результаты в сочетании с технологиями Big Data, опираясь на которые генерируются и принимаются определенные решения, составляются краткосрочные либо долгосрочные прогнозы и производится идентификация и диагностика проблем, при этом участие человека в данном процессе минимально [11].

В эпоху диджитализации социально-экономических процессов данные стали ключевым активом [12]. В государственных органах власти информация является основой для принятия решений, прогнозирования последствий разного рода деятельности, определения глубоких взаимозависимостей между разными элементами подконтрольных систем. Непрерывный огромный поток разнородной и неструктурированной информации о гражданах требует упорядочивания и принципиально новых методов обработки, учитывающие принципы конфиденциальности и безопасности [27]. На решение этой задачи направлены технологии больших данных (Big Data).

Посредством комплексного анализа больших массивов данных осуществляется формулирование целей, определение направлений государственной политики, мониторинг и совокупная оценка результатов [6, 28].

Направления использования Big Data для целей государственного и муниципального управления представлены в табл. 1 [4].

Внедрение больших данных в систему государственного управления требует больших инвестиций, поэтому необходима четкая стратегия осуществления плана интеграции, опирающаяся на показатели эффективности и рентабельности проекта. 
Таблица 1.

Сферы применения больших данных (составлено авторами на основе материалов [4])

\begin{tabular}{|c|c|}
\hline $\begin{array}{c}\text { Сфера } \\
\text { применения }\end{array}$ & Ожидаемые результаты \\
\hline $\begin{array}{l}\text { Здравоохра- } \\
\text { нение }\end{array}$ & $\begin{array}{l}\text { • Оценка страховых случаев; } \\
\text { • Единые карты пациентов (оперативность в принятии решений } \\
\text { в экстренных случаях); } \\
\text { • Повышение эффективности расходования средств за } \\
\text { счет более точной картины происходящего и выявления } \\
\text { зависимостей между принимаемыми мерами и результатами; } \\
\text { • Своевременное реагирование на сезонный рост заболевания } \\
\text { (выявление эпидемий). }\end{array}$ \\
\hline $\begin{array}{l}\text { Строитель- } \\
\text { ство }\end{array}$ & $\begin{array}{l}\text { • Строительство транспортных магистралей (проектирование } \\
\text { и прокладка транспортных магистралей для эффективной } \\
\text { организации пассажиропотока); } \\
\text { • Качественное улучшение генпланов поселений. }\end{array}$ \\
\hline Транспорт & $\begin{array}{l}\text { • Оценка транспортных потоков и пассажиропотока } \\
\text { (сокращение времени в пути для жителей страны, экономия на } \\
\text { билетах); } \\
\text { • Определение динамики и выявление причин развития проблем } \\
\text { на основе архивных, реальных и прогнозных данных; } \\
\text { • Учет результатов моделирования при проектировании } \\
\text { транспортной инфраструктуры. }\end{array}$ \\
\hline $\begin{array}{l}\text { Экономиче- } \\
\text { ская безопас- } \\
\text { ность }\end{array}$ & $\begin{array}{l}\text { • Пресечение незаконного импорта и, как следствие, повышение } \\
\text { таможенных сборов; } \\
\text { • Оптимизация функций налоговых служб (выявление различных } \\
\text { мошеннических схем, подтверждение дохода физлиц и т. д. без } \\
\text { трудоемких процедур верификации, андеррайтинга и т. п.). } \\
\text { • Выявление случаев использования инсайдерской информации } \\
\text { в торговле ценными бумагами. }\end{array}$ \\
\hline $\begin{array}{l}\text { Обществен- } \\
\text { ная безопас- } \\
\text { ность }\end{array}$ & $\begin{array}{l}\text { • Государственная безопасность; } \\
\text { • Превентивное выявление лиц, склонных к повторным } \\
\text { правонарушениям, оценка эффекта от нарушений, оптимизация } \\
\text { сил МВД. }\end{array}$ \\
\hline $\begin{array}{l}\text { Земельные } \\
\text { ресурсы }\end{array}$ & • Исключение незаконных операций с природными ресурсами. \\
\hline $\begin{array}{l}\text { Социальные } \\
\text { эффекты }\end{array}$ & $\begin{array}{l}\text { • Развитие объектов культурно-исторического значения с } \\
\text { учетом анализа туристических потоков; } \\
\text { • Выявление новых туристических направлений для развития и } \\
\text { инвестирования; } \\
\text { • Оценка настроения в обществе. }\end{array}$ \\
\hline
\end{tabular}




\section{Системы распределенного реестра}

Технология распределенного реестра (блокчейн) способна искоренить консервативную систему бюрократии, формируя при этом прозрачную систему государственных услуг, что исключает вероятность распространения коррупционных схем [20]. Данная технология представляет собой базу данных, в которой осуществляется хранение и обновление информационных данных участниками большой сети независимо друг от друга [2]. Каждый узел в сети производит обработку каждой транзакции, делая определенные выводы, на основе которых формируется блок. После создания блока на следующем этапе он проверяется другими участниками сети. Если все участники приходят к согласию, то блок присоединяется к последнему блоку цепочки, сформированному по такому же принципу. Далее распределенный реестр обновляется, но при этом узлы сохраняют свою идентичную копию, и внести какие-либо изменения в реестр становится невозможным. Помимо этого, информация в блоках хранится и обрабатывается в зашифрованном виде, что полностью исключает вероятность удаления или подмены данных о сделке в результате взлома звеньев блокчейна [7].

Высокая степень конфиденциальности и надежность хранения данных о цифровых объектах позволяет объективно оценивать и подтверждать юридические факты в решении гражданских вопросов, базируясь на не подлежащих изменению данных блокчейна $[28,23]$.

Системы распределенного реестра имеют потенциал развития не только в решении юридических вопросов судебного характера, но и во многих других сферах, среди которых документооборот, земельный кадастр, международная торговля, регистрация бизнеса. Помимо этого, систему блокчейна перспективно использовать на федеральных, региональных и муниципальных выборах с целью обеспечения прозрачности голосования [8]. Более подробно эффекты применения технологии представлены в таблице 2.

Благодаря технологиям распределенного реестра можно добиться повышения уровня защиты государственных баз данных от злоумышленников, быстрого и оперативного межведомственного взаи- 
модействия, организации эффективного управления информацией о физических и юридических лицах и осуществляемой ими деятельности [17, 23].

Таблицуа 2.

Направления использования блокчейна

\begin{tabular}{|c|c|}
\hline $\begin{array}{c}\text { Направление } \\
\text { использования }\end{array}$ & Ожидаемые результаты \\
\hline Здравоохранение & $\begin{array}{l}\text { • Обмен конфиденциальной информацией между участни- } \\
\text { ками системы здравоохранения в режиме реального вре- } \\
\text { мени; } \\
\text { • Обеспечение онлайн-доступа специалистам к медицинской } \\
\text { карте пациента; } \\
\text { • Защита информации о пациенте от посторонних лиц. }\end{array}$ \\
\hline $\begin{array}{l}\text { Голосование } \\
\text { на выборах }\end{array}$ & $\begin{array}{l}\text { • Облегчение процедуры подсчета голосов участников; } \\
\text { • Обеспечение прозрачности голосования; } \\
\text { • Предотвращение фальсификации результатов выборов. }\end{array}$ \\
\hline $\begin{array}{l}\text { Налоговая } \\
\text { сфера }\end{array}$ & $\begin{array}{l}\text { - Регистрация информации о доходах физического/юридиче- } \\
\text { ского в режиме реального времени; } \\
\text { • Невозможность уклонения от автоматизированного нало- } \\
\text { гообложения. }\end{array}$ \\
\hline $\begin{array}{l}\text { Кадастровый } \\
\text { учет }\end{array}$ & $\begin{array}{l}\text { - Упрощение регистрации земельного участка; } \\
\text { • Повышение интереса инвесторов к вложениям в земельные } \\
\text { участки; } \\
\text { • Прозрачность проведения операций. }\end{array}$ \\
\hline Документооборот & $\begin{array}{l}\text { - Гарантия конфиденциального хранения документов огра- } \\
\text { ниченного доступа; } \\
\text { - Устранение незаконных схем при продаже имущества; } \\
\text { - Сокращение продолжительности оформления документов; } \\
\text { - Уменьшение расходов на бумагу. }\end{array}$ \\
\hline $\begin{array}{l}\text { Регистрация } \\
\text { бизнеса }\end{array}$ & $\begin{array}{l}\text { • Регистрация предприятий в онлайн-режиме; } \\
\text { • Автоматизирование процесса оформления документов; } \\
\text { • Хранение сведений о держателях ценных бумаг. }\end{array}$ \\
\hline $\begin{array}{l}\text { Управление } \\
\text { финансами }\end{array}$ & $\begin{array}{l}\text { - Алгоритмическое формирование и исполнение плана рас- } \\
\text { ходов и доходов на базе смарт-контрактов; } \\
\text { - Выявление нарушений путем автоматизированного ана- } \\
\text { лиза полной и неизменной транзакционной цепи движения } \\
\text { денежных средств. }\end{array}$ \\
\hline Госзакупки & $\begin{array}{l}\text { • Обеспечение антимонопольного регулирования } \\
\text { контроль коммуникаций между поставщиками и заказчиком } \\
\text { на основе заключения смарт-контрактов; } \\
\text { • Оптимизация процесса оформления банковских гарантий; } \\
\text { • Исключение мошеннических сделок. }\end{array}$ \\
\hline
\end{tabular}




\section{Квантовые технологии}

В контексте цифровой трансформации информационное сообщество находится на стадии второй квантовой революции, которая стала движущей силой развития таких областей в квантовой теории, как квантовые коммуникационные сети, криптография, сенсорика, квантовые вычисления [7]. В основе современных квантовых технологий лежит управление квантовыми сетями на уровне отдельных элементарных частиц. Особенно ценны квантовые компьютеры, имеющие мощнейшие вычислительные системы. В отличие от традиционных компьютеров, оперирующих двоичным кодом, принцип работы квантовых построен на так называемых «кубитах», которые могут принимать более двух значений в пределах нуля и единицы (суперпозиция).

Квантовые технологии способны обеспечить национальную безопасность государства. Поэтому государство выступает главным заказчиком разработки проектов по развитию стратегически важных для него квантовых технологий. Данные технологии способствуют эффективному решению таких задач, стоящих перед государством, как борьба с киберпреступностью, использование квантовых вычислений в автомобильной и оборонной промышленности, увеличение объема государственных инвестиций. Успешная реализация проектов по интеграции квантовых технологии в управление выведет государство на принципиально новый уровень безопасности [28].

Квантовые технологии также рассматриваются в аспекте улучшения каналов связи. По мере их развития станет возможным появление супербыстрого квантового интернета в рамках организация межконтинентальной сети, что послужит более эффективной коммуникации между государственными органами разных стран для обсуждения задач международного значения [3, 12, 23].

Внедрение квантовых технологий в сферу медицины повысит уровень организации системы здравоохранения. К примеру, используя квантовые сенсоры в медицинском оборудовании для диагностики здоровья граждан, вероятность поставить точный диагноз за короткий срок возрастет в разы. 
Квантовые технологии до конца не изучены. Требуется проведение многочисленных исследовательских работ, чтобы устранить возможные уязвимости при внедрении данных технологий в систему государственного управления. Однако, они имеют огромный потенциал использования и могут существенно повысить качество жизни населения.

\section{Обсуждение}

Тренд цифровизации связан с серьезными вызовами как для государства, так и для общества. Внедрение «сквозных» цифровых технологий в систему государственного управления имеет как выгоды, так и определенные риски. В таблице 3 , составленной авторами, представлено соотношение преимуществ и возможных отрицательных исходов.

\section{Выгоды и риски интеграции цифровых технологий}

Таблица 3.

в государственное управление

\begin{tabular}{|c|c|c|}
\hline & Выгоды & Риски \\
\hline $\begin{array}{l}\text { Для госу- } \\
\text { дарства }\end{array}$ & $\begin{array}{l}\text { - Быстрое и оперативное межведомствен- } \\
\text { ное взаимодействие } \\
\text { • Повышение уровня защиты государствен- } \\
\text { ных баз данных от злоумышленников } \\
\text { - Эффективное управление информацией } \\
\text { о физических и юридических лицах и осу- } \\
\text { ществляемой ими деятельности } \\
\text { - Обеспечение национальной безопасности } \\
\text { - Упрощение задач налогообложения и } \\
\text { финансового контроля } \\
\text { - Определение направлений государствен- } \\
\text { ной политики на основе непрерывного } \\
\text { мониторинга и совокупной оценки резуль- } \\
\text { татов реализации федеральных программ }\end{array}$ & $\begin{array}{l}\text { • Необходимость в } \\
\text { крупных финансовых } \\
\text { вложениях, которые } \\
\text { могут не окупиться } \\
\text { • Увеличение числа со- } \\
\text { кращения чиновников } \\
\text { • Вероятность ошибок } \\
\text { в нормативно-правовой } \\
\text { и организационно-ме- } \\
\text { тодической базах } \\
\text { • Недостаток квалифи- } \\
\text { цированных специали- } \\
\text { стов в области цифро- } \\
\text { вых технологий }\end{array}$ \\
\hline $\begin{array}{l}\text { Для об- } \\
\text { щества }\end{array}$ & $\begin{array}{l}\text { - Быстрая и качественная обработка обра- } \\
\text { щений граждан } \\
\text { • Упрощение бюрократического механизма } \\
\text { • Исключение распространения коррупци- } \\
\text { онных схем } \\
\text { • Возможность прозрачного голосования } \\
\text { на выборах } \\
\text { • Повышение качества жизни }\end{array}$ & $\begin{array}{l}\text { - Проблема обеспечения } \\
\text { прав в цифровом мире } \\
\text { • Несанкционирован- } \\
\text { ное использование ин- } \\
\text { формации о гражданах, } \\
\text { кража данных } \\
\text { • Рост масштабов ки- } \\
\text { берпреступности }\end{array}$ \\
\hline
\end{tabular}




\section{Заключение}

Использование «сквозных» цифровых технологий в совокупности приведет к созданию мощной государственной системы управления, которая будет в полной мере отвечать требованиям современного общества. Цифровая трансформация механизмов осуществления управленческих функций и задач имеет ряд преимуществ, среди которых повышение эффективности государственного контроля и высокий уровень удовлетворенности граждан качеством предоставления госуслуг [8]. Новая технологическая парадигма вызывает необходимость переформирования иерархии органов власти, предлагая создание архитектуры государства на базе единой платформы [3, 6, 16, 23].

Многие развитые и развивающиеся страны, в том числе Россия поставили перед собой цель прийти к масштабной оцифровке инфраструктуры государства за счет активной интеграции передовых технологий $[1,5]$. Основные мероприятия по цифровизации государственного управления в России сформулированы в федеральном проекте «Цифровое государственное управление», включенном в состав национального проекта «Цифровая экономика Российской Федерации» [19]. Однако реализация программы по цифровой трансформации требует значительных инвестиционных вложений, которые не всегда могут окупиться по причине довольно высоких рисков. Чтобы прийти к государству будущего, фундаментом которого является платформа, построенная при помощи «сквозных» цифровых технологий, необходимо произвести глобальную реорганизацию устоявшейся иерархии аппарата управления и отказаться от консервативных парадигм. Цифровизация государственного управления требует повышения квалификации государственных служащих в аспекте цифровой культуры и способна дать мощный импульс развитию цифровой экономики в стране.

\section{Список литературы}

1. Авцинова Г.И. Политика цифровизации в современной России: особенности формирования и перспективы развития // PolitBook. 2019. № 4. C. 6-20. 
2. Белоусов А.Л., Шустров А.А. Возможности применения технологии блокчейн в сфере страхования // Финансы и кредит. 2019. Т. 25. № 1 (781). С. 196-210.

3. Большаков С.Н., Лескова И.В., Большакова Ю.М. Цифровая экономика как составляющая технологической платформы государственной политики и управления // Вопросы управления. 2017. № 1. С. 64--70.

4. Большие данные в государственном управлении: опыт внедрения [Электронный ресурс]. http://window.edu.ru/resource/636/75636/files/ Analysis_Center.pdf (дата обращения: 17.10.2020).

5. Всемирный банк. Цифровое правительство 2020. Перспективы для России [Электронный ресурс]. http:/www.iis.ru/docs/ DigitalGovernmentRussia2020RUS.pdf (дата обращения: 17.10.2020).

6. Выжимова Н.Г., Иванова Е.Ю., Колесниченко Е.А. Цифровизация управления как фактор развития современного государства // Бюллетень науки и практики. 2018. Т. 4. № 5. С. 465-473.

7. Глазьев С.Ю. Перспективы становления в мире нового VI технологического уклада // Мир (Модернизация. Инновации. Развитие). 2010. №2. C. 4-10.

8. Днепровская Н.В. Цифровая трансформация взаимодействия органов государственной власти и граждан // Государственное управление. Электронный вестник. 2018. № 67. С. 96-110.

9. Добролюбова Е.И. Методические подходы к оценке выгод от цифровизации государственного управления для граждан // Вопросы управления. 2019. № 5 (60). С. 51-62.

10. Добролюбова Е.И., Южаков В.Н., Ефремов А.А., Клочкова Е.Н., Талапина Э.В., Старцев Я.Ю. Цифровое будущее государственного управления по результатам. Изд. дом «Дело» РАНХиГС, 2019. С. 114.

11. Касьянов С.В. Цифровая трансформация как новый драйвер повышения результативности в системе государственного и муниципального управления // Региональные проблемы преобразования экономики. 2019. № 9 (107). С. 5.

12. Корчагин С., Польшиков Б. Цифровая экономика и трансформация механизмов государственного управления. Риски и перспективы для России // Свободная мысль. 2018. № 1 (1667). С. 23-36. 
13. Котляров И.Д. Применение аутсорсинга в государственной деятельности в Российской Федерации // Вопросы государственного и муниципального управления. 2012. №2. С. 112-120.

14. Кузнецов Н.В., Лесных Ю.Г. Цифровизация информационной поддержки принятия решений в сфере государственного управления // Общество: политика, экономика, право. 2020. № 1 (78). С. 30-35.

15. Лопатова Н. Международный опыт формирования цифрового правительства // Наука и инновации. 2019. № 5 (195). С. 24-28.

16. Меденников В.И. Принципы формирования единой цифровой платформы страны // Цифровая экономика. 2018. № 4. С. 31-37.

17.Наумов В.Б. Общие вызовы права и государственного управления в цифровую эпоху // Ленинградский юридический журнал. 2019. № 1 (55). C. 43-57.

18. Министерство цифрового развития, связи и массовых коммуникаций Российской Федерации [Электронный ресурс]. https:/digital.gov.ru/ ru/activity/directions/878/ (дата обращения: 17.10.2020).

19. Паспорт федерального проекта «Цифровое государственное управление» национальной программы «Цифровая экономика РФ» [Электронный ресурс]. https://files.data-economy.ru/Docs/FP_Cifrovoe gosudarstvennoe_upravlenie.pdf (дата обращения: 19.10.2020).

20. Пестунов А.И. Криптовалюты и блокчейн: потенциальные применения в государстве и бизнесе // ЭКО. 2018. № 8 (530). С. 78-92.

21.Плотников В.А. Цифровизация как закономерный этап эволюции экономической системы // Экономическое возрождение России. 2020. №2 (64). С. 104-115.

22. Поветкина Н.А., Леднева Ю.В. «Финтех» и «Регтех»: границы правового регулирования // Право. Журнал Высшей школы экономики. 2018. № 2. С. 46-67.

23. Пролубников А.В. Платформенная модель государственной экономической политики // Многоуровневое общественное воспроизводство: вопросы теории и практики. 2020. № 18 (34). С. 21-33.

24. Сидоренко Э.Л., Барциц И.Н., Хисамова З.И. Эффективность цифрового государственного управления: теоретические и прикладные аспекты // Вопросы государственного управления. 2019. №2. С. 93-114. 
25.Ситникова В.Ф. Цифровые технологии в контрольно-надзорной деятельности // Современная наука: проблемы и перспективы развития. Сборник статей IV Международной научно-практической конференции. В 3-х частях. Под редакцией А.Э. Еремеева. 2020. C. $100-105$.

26. Устюжанина Е.В., Сигарев А.В., Шеин Р.А. Цифровая экономика как новая парадигма экономического развития // Экономический анализ: теория и практика. 2017. Т. 16. №12 (471). С. 2238-2253.

27. Федеральный закон «Об информации, информационных технологиях и о защите информации» от 27.07.2006 №149-Ф3 (последняя редакция).

28. «Цифровая Россия: новая реальность», отчет 2017, июль [Электронный pecypc]. https://www.mckinsey.com/ru/our-insights (дата обращения: 17.10.2020).

29. Шваб К. Четвертая промышленная революция. Эксмо, 2016. С. 208.

\section{References}

1. Avcinova G.I. Politika cifrovizacii v sovremennoj Rossii: osobennosti formirovaniya i perspektivy razvitiya [The policy of digitalization in modern Russia: features of formation and prospects of development]. PolitBook, 2019, no. 4, pp. 6-20.

2. Belousov A.L., Shustrov A.A. Vozmozhnosti primeneniya tekhnologii blokchejn v sfere strahovaniya [Possibilities of using blockchain technology in the insurance industry]. Finance and credit, 2019, vol. 25, no. 1 (781), pp. 196-210.

3. Bol'shakov S.N., Leskova I.V., Bol'shakova Yu.M. Cifrovaya ekonomika kak sostavlyayushchaya tekhnologicheskoj platformy gosudarstvennoj politiki i upravleniya [Digital economy as a component of the technological platform of state policy and management]. Management issue, 2017, no. 1, pp. 64-70.

4. Bol'shie dannye $v$ gosudarstvennom upravlenii: opyt vnedreniya [Big data in public administration: the experience of implementation], www.window.edu.ru [Electronic resource]. http://window.edu.ru/resource/636/75636/files/Analysis_Center.pdf (accessed 17.10.2020). 
5. Vsemirnyj bank. Cifrovoe pravitel'stvo 2020. Perspektivy dlya Rossii [World bank. Digital government 2020. prospect for Russia], www.iis. $\mathrm{ru}$ [Electronic resource]. http://www.iis.ru/docs/DigitalGovernmentRussia2020RUS.pdf (accessed: 17.10.2020).

6. Vyzhimova N.G., Ivanova E.Yu., Kolesnichenko E.A. Cifrovizaciya upravleniya kak faktor razvitiya sovremennogo gosudarstva [Digitalization of management as a factor of development of the modern state]. Byulleten' nauki i praktiki, 2018, vol. 4, no. 5, pp. 465-473.

7. Glaz'ev S.Yu. Perspektivy stanovleniya v mire novogo VI tekhnologicheskogo uklada [Prospects for the formation of a new VI technological order in the world]. Mir (Modernization. Innovations. Development), 2010. no. 2, pp. 4-10.

8. Dneprovskaya N.V. Cifrovaya transformaciya vzaimodejstviya organov gosudarstvennoj vlasti i grazhdan [Digital transformation of interaction between state authorities and citizens]. State administration. Electronic Bulletin, 2018, no. 67, pp. 96-110.

9. Dobrolyubova E.I. Metodicheskie podhody k ocenke vygod ot cifrovizacii gosudarstvennogo upravleniya dlya grazhdan [Methodological approaches to assessing the benefits of digitalization of public administration for citizens]. Management issue, 2019, no. 5 (60), pp. 51-62.

10.Dobrolyubova E.I., Yuzhakov V.N., Efremov A.A., Klochkova E.N., Talapina E.V., Starcev Ya.Yu. Cifrovoe budushchee gosudarstvennogo upravleniya po rezul 'tatam [Digital future of public administration by results]. Publishing house "Delo" Ranepa, 2019, p. 114.

11. Kas'yanov S.V. Cifrovaya transformaciya kak novyj drajver povysheniya rezul'tativnosti v sisteme gosudarstvennogo i municipal'nogo upravleniya [Digital transformation as a new driver for improving performance in the system of state and municipal management]. Regional problems of economic transformation, 2019, no. 9 (107), p. 5.

12. Korchagin S., Pol'shikov B. Cifrovaya ekonomika i transformaciya mekhanizmov gosudarstvennogo upravleniya. Riski i perspektivy dlya Rossii [Digital economy and transformation of public administration mechanisms. Risks and prospects for Russia]. Free thought, 2018, no. 1 (1667), pp. 23-36. 
13. Kotlyarov I.D. Primenenie autsorsinga v gosudarstvennoj deyatel'nosti v Rossijskoj Federacii [Application of outsourcing in state activities in the Russian Federation]. Issues of state and municipal administration, 2012, no. 2, pp. 112-120.

14. Kuznecov N.V., Lesnyh Yu.G. Cifrovizaciya informacionnoj podderzhki prinyatiya reshenij $\mathrm{v}$ sfere gosudarstvennogo upravleniya [Digitalization of information support for decision-making in the sphere of public administration]. Society: politics, Economics, law, 2020, no 1 (78), pp. 30-35.

15. Lopatova N. Mezhdunarodnyj opyt formirovaniya cifrovogo pravitel'stva [International experience in forming a digital government]. Science and innovation, 2019, no. 5 (195), pp. 24-28.

16. Medennikov V.I. Principy formirovaniya edinoj cifrovoj platformy strany [Principles of forming a unified digital platform of the country]. Digital economy, 2018, no. 4, pp. 31-37.

17. Naumov V.B. Obshchie vyzovy prava i gosudarstvennogo upravleniya $\mathrm{v}$ cifrovuyu epohu [General challenges of law and public administration in the digital age]. Leningrad legal journal, 2019, no. 1 (55), pp. 43-57.

18. Ministerstvo cifrovogo razvitiya, svyazi i massovyh kommunikacij Rossijskoj Federacii [Ministry of digital development, communications and mass media of the Russian Federation], https://digital.gov.ru [Electronic resource]. https://digital.gov.ru/ru/activity/directions/878/ (accessed: 17.10.2020).

19. Pasport federal'nogo proekta «Cifrovoe gosudarstvennoe upravlenie» nacional'noj programmy "Cifrovaya ekonomika $R F$ » [Passport of the Federal project "Digital public administration" of the national program "Digital economy of the Russian Federation»], www.files.data-economy. ru [Electronic resource]. https://files.data-economy.ru/Docs/FP_Cifrovoe_gosudarstvennoe_upravlenie.pdf (accessed: 19.10.2020).

20. Pestunov A.I. Kriptovalyuty i blokchejn: potencial'nye primeneniya v gosudarstve i biznese [Cryptocurrencies and blockchain: potential applications in the state and business]. ECO, 2018, no. 8 (530), pp. 78-92.

21. Plotnikov V.A. Cifrovizaciya kak zakonomernyj etap evolyucii ekonomicheskoj sistemy [Digitalization as a natural stage in the evolution of the economic system]. Economic revival of Russia, 2020, no.2 (64), pp. 104-115. 
22. Povetkina N.A., Ledneva Yu.V. «Fintekh» $\mathrm{i}$ «Regtekh»: granicy pravovogo regulirovaniya [«FINTECH» and «Regtech»: boundaries of legal regulation]. Law. Journal of the Higher school of Economics, 2018, no. 2, pp. 46-67.

23. Prolubnikov A.V. Platformennaya model' gosudarstvennoj ekonomicheskoj politiki [Platform model the state economic policy]. Multilevel social reproduction: questions of theory and practice, 2020, no 18 (34), pp. 21-33.

24. Sidorenko E.L., Barcic I.N., Hisamova Z.I. Effektivnost' cifrovogo gosudarstvennogo upravleniya: teoreticheskie i prikladnye aspekty [Digital public administration: theoretical and applied aspects]. Public administration issues, 2019, no. 2, pp. 93-114.

25. Sitnikova V.F. Cifrovye tekhnologii v kontrol'no-nadzornoj deyatel'nosti [Digital technologies in control and supervision activities]. Sovremennaya nauka: problemy i perspektivy razvitiya. Sbornik statej IV Mezhdunarodnoj nauchno-prakticheskoj konferencii [Modern science: problems and development prospects. Collection of articles of the IV International Scientific and Practical Conference]. Ed. A.E. Eremeev, 2020, pp. 100-105.

26. Ustyuzhanina E.V., Sigarev A.V., Shein R.A. Cifrovaya ekonomika kak novaya paradigma ekonomicheskogo razvitiya [Digital economy as a new paradigm of economic development]. Economic analysis: theory and practice, 2017, vol. 16, no. 12 (471), pp. 2238-2253.

27.Federal'nyj zakon "Ob informacii, informacionnyh tekhnologiyah i o zashchite informacii» ot 27.07.2006 №149-FZ (poslednyaya redakciya) [Federal Law "On Information, Information Technologies and Information Protection" dated July 27, 2006 No. 149-FZ (last edition)].

28. "Cifrovaya Rossiya: novaya real'nost'», otchet 2017, iyul' ["Digital Russia: a new reality", report 2017, July], www.mckinsey.com [Electronic resource]. https://www.mckinsey.com/ru/our-insights (accessed: 17.10.2020).

29. SHvab K. CHetvertaya promyshlennaya revolyuciya [The Fourth industrial revolution]. Eksmo, 2016, p. 208. 


\section{ДАННЫЕ ОБ АВТОРАХ}

Катрашова Юлия Валентиновна, бакалавр направления "Государственное и муниципальное управление”

Федеральное государственное автономное образовательное учреждение высшего образования «Санкт-Петербургский политехнический университет Петра Великого»

ул. Политехническая, 29, г. Санкт-Петербург, 194064, Российская Федерация

ul.katrashova@gmail.com

Митяшин Глеб Юрьевич, бакалавр направления “Торговое дело” Федеральное государственное автономное образовательное учреждение высшего образования «Санкт-Петербургский политехнический университет Петра Великого»

ул. Политехническая, 29, г. Санкт-Петербург, 194064, Российская Федерация

gleb.mityashin@yandex.ru

\section{DATA ABOUT THE AUTHORS}

Katrashova Yuliya Valentinovna, Bachelor of "Public administration" Peter the Great St. Petersburg Polytechnic University 29, Politekhnicheskaya Str., St. Petersburg, 194064, Russian Federation ul.katrashova@gmail.com

Mityashin Gleb Yurievich, Bachelor of "Trade"

Peter the Great St. Petersburg Polytechnic University 29, Politekhnicheskaya Str., St. Petersburg, 194064, Russian Federation gleb.mityashin@yandex.ru 